\title{
Pharmacological Response in Male Rats with Controlled Release Formulations of Luteinizing Hormone- Releasing Hormone Agonist
}

\author{
Masaru YoshIDA, Masaharu AsANO, Isao KAETSU, \\ Kyoichi IMAI, ${ }^{*}$ Hisako YUASA, ${ }^{*}$ Hidetoshi YamanaKa, ${ }^{*}$ \\ Keizo ShIDA, ${ }^{*}$ Keiji SuZUKI, ${ }^{* *}$ Katsumi WAKABAYASHI, ${ }^{* * *}$ \\ and Iwao YAMAZAKI**** \\ Takasaki Radiation Chemistry Research Establishment, \\ Japan Atomic Energy Research Institute, \\ Takasaki, Gunma 370-12, Japan \\ * Department of Urology, School of Medicine, Gunma University, \\ Maebashi, Gunma 371, Japan \\ ** Department of Pathology, College of Medical Care and Technology, \\ Gunma University, Maebashi, Gunma 371, Japan \\ ***Hormone Assay Center, Institute of Endocrinology, Gunma University, \\ Maebashi, Gunma 371, Japan \\ ****Central Research Division, Takeda Chemical Industries, Ltd., \\ Osaka 532, Japan
}

(Received September 19, 1985)

\begin{abstract}
A synthetic nonapeptide agonist of luteinizing hormone-releasing hormone ( $\mathrm{LH}$ $\mathrm{RH})$, des-Gly ${ }^{10}$-[D-Leu $]$ - $\mathrm{LH}-\mathrm{RH}$ ethylamide, was entrapped in a nonbiodegradable copolymer of hydrophobic diethylene glycol dimethacrylate and hydrophilic polyethylene glycol \#600 dimethacrylate having a sandwich-type structure prepared by radiation-induced polymerization. The two types of controlled release formulations prepared in this study have average release rates of 7 and $320 \mu \mathrm{g} /$ day in the in vivo experiments. In this case, the controlled release formulations implanted subcutaneously in the backs of male Wistar rats were maintained over a period of 10 weeks. Serum drug levels were found to be 2.6 and $30 \mathrm{ng} \mathrm{ml}^{-1}$ respectively and were constant throughout the experimental period. The serum testosterone level and serum LH level were significantly reduced to castrated values at 2 weeks after implantation. At the same time, the ventral prostates, seminal vesicles, and dorsolateral prostates also showed a considerable decrease in weight. These data show excellent therapeutic potential of LH-RH agonist in controlled release formulations.
\end{abstract}

KEY WORDS Luteinizing Hormone-Releasing Hormone Agonist / Nonbiodegradable Vinyl Copolymer / Serum Drug Level / Male Wistar Rat / Controlled Release Formulation / Implantation / In Vitro-In Vivo Release of Drug / Pharmacological Response / Radiation-Induced Polymerization /

A nonbiodegradable vinyl copolymer from hydrophobic diethylene glycol dimethacrylate and hydrophilic polyethylene glycol \#600 dimethacrylate, prepared by radiation-induced copolymerization at low temperature, has good biocompatibility as a carrier for drug delivery systems. ${ }^{1-5}$ However, this carrier must be removed from a living body after the complete release of the drug. Therefore, the release of drugs from this formulation must occur over a period of several years in order to reduce the time of surgical implantation. Such formulations have been already made by several workers using water-insoluble drugs 
such as estradiol, ${ }^{6,8}$ progesterone, ${ }^{7} \mathrm{~N}$-(2-chloromethyl-2-hydroxypropionyl)-3,4,5-trichloroaniline, ${ }^{8}$ and chloromadinone. ${ }^{8}$ For watersoluble drug systems, no study has been reported on the controlled slow release of drugs over long periods of time. The mechanism for the release of water-soluble drugs is divided into three processes, that is, rapid release in the initial stage, then steady release over most of the test period, and slow release in the final stages. Such release behavior makes it difficult to keep the concentration of drug at a constant level. It is most important to develop formulations suitable for the release of water-soluble drugs at an apparent zero-order rate. To solve this problem, the preparation of a sandwich structure has been investigated.

The water-soluble drug used in this study was a synthetic nonapeptide analogue of $\mathrm{LH}$ RH, des-Gly ${ }^{10}$-[D-Leu $\left.{ }^{6}\right]-\mathrm{LH}-\mathrm{RH}$ ethylamide. This compound was 80 to 100 times more potent than the natural $\mathrm{LH}-\mathrm{RH}$ in the release function of $\mathrm{LH}$, and the chronic treatment with LH-RH agonist results in the inhibition of both pituitary and leydig cell function, accompanied by the decrease of testes, seminal vesicles, and prostate weights. ${ }^{9-12}$ The pharmacological response of this drug in animal and clinical cases appeared only in every day administrations and to keep the efficacy, it had to be administered over a long period.

The drug powder was pressed at a pressure of $400 \mathrm{~kg} \mathrm{~cm}^{-2}$ in tablet form, placed between two filter papers, and then composed with a copolymer by radiation-induced copolymerization of monomers in the supercooled state at $-78^{\circ} \mathrm{C}$ to form the sandwich structure. The product was implanted subcutaneously in the backs of male Wistar rats at a maximum for 10 weeks. Various effects such as in vitro and in vivo releases of drugs from this sandwich formulation, serum drug level, serum testosterone level, serum LH level, and pharmacological response in rat prostate were investigated. The histopathological findings of the carrier itself were also investigated.

\section{EXPERIMENTAL}

\section{Materials}

L-Pyroglutamyl-L-hystidyl-L-tryptophyl-Lseryl-L-tyrosyl-D-leucyl-L-leucyl-L-arginylL-proline ethylamide monoacetate, des-Gly ${ }^{10}$ [D-Leu ${ }^{6}$-LH-RH ethylamide, as a LH-RH agonist was obtained from Takeda Chemical Industries, Ltd. This compound, which has the chemical structure in Figure la, is a white crystal and is readily soluble in aqueous solutions or lower alcohols. Hydrophobic diethylene glycol dimethacrylate, $\mathrm{CH}_{2}=\mathrm{C}\left(\mathrm{CH}_{3}\right)$ $\mathrm{COO}\left(\mathrm{CH}_{2} \mathrm{CH}_{2} \mathrm{O}\right)_{2} \mathrm{OC}\left(\mathrm{CH}_{3}\right) \mathrm{C}=\mathrm{CH}_{2}$, and hydrophilic polyethylene glycol \#600 dimethacrylate, $\quad \mathrm{CH}_{2}=\mathrm{C}\left(\mathrm{CH}_{3}\right) \mathrm{COO}\left(\mathrm{CH}_{2} \mathrm{CH}_{2} \mathrm{O}\right)_{14} \mathrm{OC}$ $\left(\mathrm{CH}_{3}\right) \mathrm{C}=\mathrm{CH}_{2}$, as carriers were obtained from Shin-Nakamura Chemical Co., Ltd. and purified according to the previously described method. ${ }^{2}$

\section{Preparation of Controlled Release Formula- tions of LH-RH Agonist Having Sandwich Structures}

The controlled release formulations having sandwich structures were prepared according to the schematic diagram in Figure 2. Fifty $\mathrm{mg}$ of drug powder were treated at $25^{\circ} \mathrm{C}$ for 3 minutes under a pressure of $400 \mathrm{~kg} \mathrm{~cm}^{-2}$ with a mould (Figure 2(1)) into a rigid tablet form $(11 \mathrm{~mm}$ in diameter and $0.60 \mathrm{~mm}$ thick). Then it was inserted between two Whatman No. 1 filter papers as membrane filters $(13 \mathrm{~mm}$ in diameter and $0.18 \mathrm{~mm}$ thick), placed on the bottom of a glass ampoule mould ( $14 \mathrm{~mm}$ in an inside diameter) as shown in Figure 2(3). A comonomer $(0.6 \mathrm{ml})$ of $80 \%$ diethylene glycol dimethacrylate- $20 \%$ poly(ethylene glycol) \#600 dimethacrylate composition was charged into the ampoule and sealed off under nitrogen gas (Figure 2(4)). The ampoule was irradiated for $3 \mathrm{~h}$ at a dose rate of $5 \times 10^{5} \mathrm{rad} \mathrm{h}^{-1}$ with gamma-ray from a ${ }^{60} \mathrm{Co}$ source, at $-78^{\circ} \mathrm{C}$ (dry ice-methanol system). The comonomer in the supercooled state was completely polymerized by the above irradiation. The water content of 


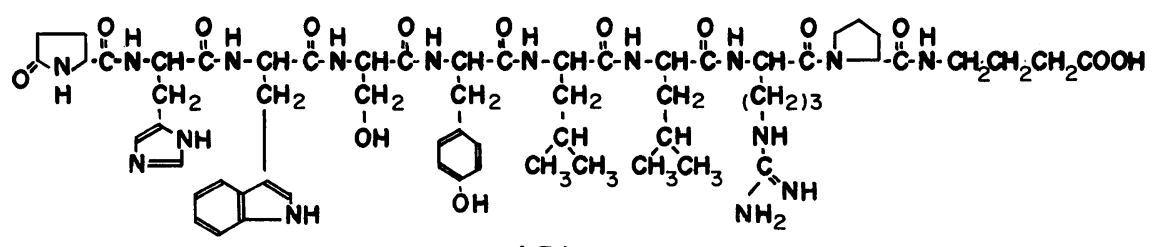

(a)

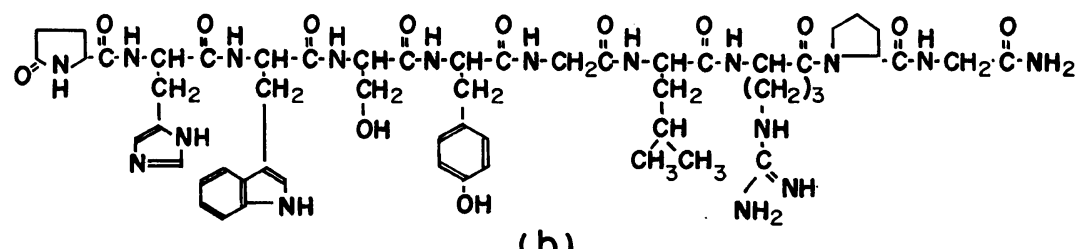

(b)

Figure 1. Chemical structure of LH-RH agonist used in this study. (a) LH-RH agonist, (b) natural LHRH.

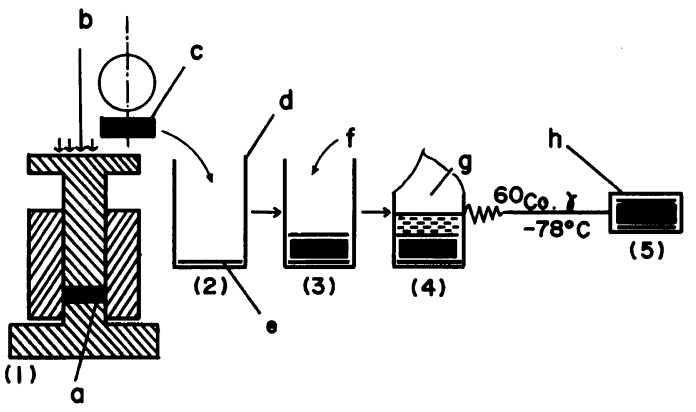

Figure 2. Schematic diagram for preparation of controlled release formulations of LH-RH agonist having sandwich structures. (a) drug powder $(50 \mathrm{mg})$, (b) pressed for $3 \mathrm{~min}$ at a pressure of $400 \mathrm{~kg} \mathrm{~cm}^{-2}$ at $25^{\circ} \mathrm{C}$, (c) pressed drug (11 $\mathrm{mm}$ in diameter), (d) glass ampoule as a mould, (e) Whatman No. 1 filter paper as a membrane filter (13 $\mathrm{mm}$ in diameter), (f) $80 \%$ diethylene glycol dimethacrylate $-20 \%$ polyethylene glycol \#600 dimethacrylate comonomer as a carrier $(0.6 \mathrm{ml})$, $(\mathrm{g}) \mathrm{ni}-$ trogen gas, (h) controlled release formulation having sandwich structure (14 $\mathrm{mm}$ in diameter and $4 \mathrm{~mm}$ thick).

the copolymer prepared was $4.8 \%{ }^{2}{ }^{2}$ Then the product was removed from the mould and the controlled release formulation of $14 \mathrm{~mm}$ in diameter and $4 \mathrm{~mm}$ thick (Figure 2(5)) was obtained finally. In this case, the thickness of the polymeric membrane for the drug tablet $(0.60 \mathrm{~mm}$ thick $)$ encased completely in the copolymer was $0.20 \mathrm{~mm}$ thick for the lower layer and $3.20 \mathrm{~mm}$ thick for the upper layer, re- spectively. This formulation was hard and showed no change of shape even after 10 weeks implantation. The another formulation including $5 \mathrm{mg}$ of drug was also prepared in the same way, e.g., pressing the drug for $3 \mathrm{~min}$ under $400 \mathrm{~kg} \mathrm{~cm}^{-2}$ at $25^{\circ} \mathrm{C}$ into a $2 \mathrm{~mm}$ diameter tablet $(0.13 \mathrm{~mm}$ thick $)$, putting it between two Whatman No. 1 filter papers $(4 \mathrm{~mm}$ in diameter and $0.18 \mathrm{~mm}$ thick), introducing the same comonomer $(0.4 \mathrm{ml})$, and irradiating it for $3 \mathrm{~h}$ at a dose rate of $5 \times 10^{5} \mathrm{radh}^{-1}$ at $-78^{\circ} \mathrm{C}$ to form the product of $5 \mathrm{~mm}$ in diameter and $3 \mathrm{~mm}$ thick $(0.31 \mathrm{~mm}$ thick for drug tablet, $0.20 \mathrm{~mm}$ thick for polymeric membrane of the lower layer, and $2.49 \mathrm{~mm}$ thick for polymeric membrane of the upper layer).

\section{Animal Experiments}

Male Wistar rats (3 rats/group) of approximately $300-360 \mathrm{~g}$ weight were used. The sandwiched formulations of $\mathrm{LH}-\mathrm{RH}$ agonist were washed with ethanol and $1 \%$ hibitane solution for sterilization and then implanted subcutaneously in the backs of rats as shown in Figure 3. At a fixed interval of time, the animals were sacrificed and the implants were collected from the animals. The results of assay of cumulative amount of released drug in vivo will be described in a later section. 


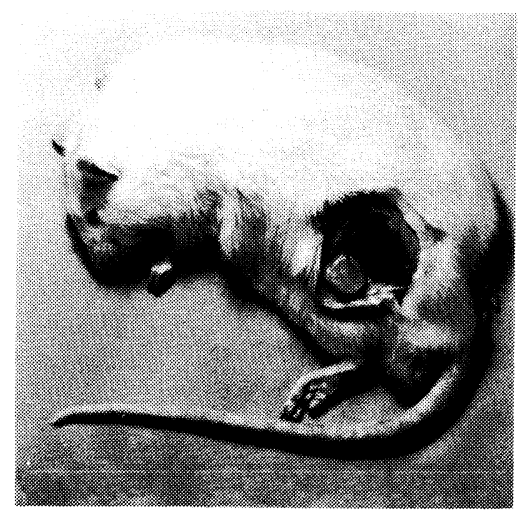

Figure 3. The site of surgical insertion of implants. The controlled release formulation was implanted subcutaneously in the backs of male Wistar rats and the animals were sacrificed at the 10 th week after implantation.

For an injection administration of LH-RH agonist, the drug was dissolved in distilled water and given to the animals at a dose of $20 \mu \mathrm{g}$ subcutaneously once a day. In this case, the animals were sacrificed $24 \mathrm{~h}$ after the final injection.

The efficacy of the LH-RH agonist was determined by the pharmacological response in male Wistar rats such as weight changes in ventral prostates, dorsolateral prostates, and seminal vesicles and also weight changes in adrenal glands and testes. They were excised separately from the sacrificed animals, pooled after freed of surrounding connective tissues, and weighed.

\section{Measurement of Serum Level of Hormones}

The radioimmunoassay for serum drug level was carried out by the double antibody technique. ${ }^{13}$ The serum testosterone level was measured by radioimmunoassay according to the method of Makino. ${ }^{14}$ Serum LH level was also determined by radioimmunoassay employing the radioimmunoassay kits. ${ }^{15}$ The radioimmunoassay kits were supplied by Dr. V. F. Parlow of Rat Pituitary Hormone Program, NIAMDD, NIH. The results were expressed as the equivalent of NIH-LH-sl for LH (s1, immunoreactive $\mathrm{LH}$ value assayed with NIAMDD anti-rat NIH-LH-sl).

\section{Release Test of LH-RH Agonist}

The daily dose of released drug was determined as follows. In the in vitro experiments, the controlled release formulation (5 samples/group) was placed in the flask containing $100 \mathrm{ml}$ of $0.1 \mathrm{M}$ phosphate buffer solution ( $\mathrm{pH} 7.2)$ as an elution medium at $37^{\circ} \mathrm{C}$. The flask was shaken at a rate of 100 times a minute. ${ }^{4}$ The drug concentration in the medium was determined at intervals spectrophotometrically at $278 \mathrm{~nm} .{ }^{5}$ The elution medium was daily exchanged with a fresh one. The cumulative amount of released drug was also calculated from the daily dose. In some cases, the formulation was taken off from the eluted medium, dried, and then pulverized into a powder. The powder was immersed in $0.1 \mathrm{M}$ phosphate buffer solution ( $\mathrm{pH}$ 7.2) to release the remaining drug completely and the amount of remaining drug was determined to estimate the cumulative amount of released drug. The difference in cumulative amounts of drug between the two estimations was within $3 \%$.

In the in vivo experiments, the implanted formulation (3 rats/group) was recovered from the sacrificed rats at intervals such as on the 1st day, 1st week, 2nd week, 4th week, 6th week, 8 th week, and 10th week. The cumulative amount of released drug was estimated from the amount of drug remaining in the formulation by the same methods as in the in vitro experiments.

\section{Microscopic Observations}

The formulation was implanted subcutaneously in the backs of rats. 10 weeks after implantation, the tissues surrounding the implant were preserved in $10 \%$ buffered formalin. The tissues for optical microscopic study were embedded in paraffin, sectioned at about $4 \mu \mathrm{m}$, stained with hematoxylin and eosin. On the other hand, the surface structure of formulation was observed with a scanning electron 
microscopy, Model JXA-733, JEOL X-ray microanalyzer.

\section{RESULTS AND DISCUSSION}

\section{Biocompatibility of Vinyl Copolymer Formu- lations}

The controlled release formulations of $\mathrm{LH}$ RH agonist were implanted subcutaneously in the backs of male Wistar rats. Figure 3 shows the site of the surgical insertion of implant. As seen in Figure 3, no inflammatory response to a foreign body appears even at 10 th weeks after implantation. This is also supported from the histopathological findings of tissues surrounding the implant in Figure 4. The microscopic observations of tissues stained with hematoxylin and eosin showed that the tissues surrounding the implant consisted mainly of thin capsules of fibrous tissues. Figure 5 shows a scanning electron microphotograph of tissue cells adherent to the surface of implanted formulation after 10 weeks. Although the microfibrils (about 100 angstrom) adhered to the surface of the formulation, the surface was not covered completely by the cells. However, in a strongly hydrophilic poly(2- hydroxyethyl methacrylate), the tissue cells adhered easily to the carrier surface to cover completely it with a thick cellular membrane. ${ }^{1}$ Such a membrane significantly retarded the in vivo release of the drug from the formulation. The changes in weight of a copolymer of diethylene glycol dimethacrylate and polyethylene glycol \#600 dimethacrylate were also investigated in the in vivo experiments. The copolymer itself in tablet form (weight per tablet: $0.2 \mathrm{~g}$, size of tablet: $8 \mathrm{~mm}$ in diameter) was implanted subcutaneously in the backs of

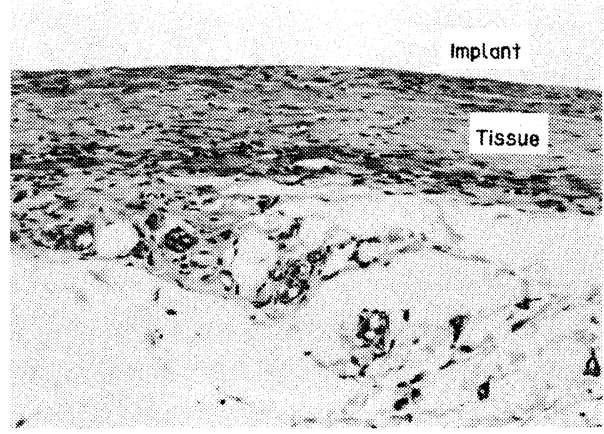

Figure 4. Optical microphotograph of rat tissues surrounding the vinyl copolymer formulations (stained with hematoxylin and eosin). The formulation was implanted subcutaneously in the backs of rats for 10 weeks.
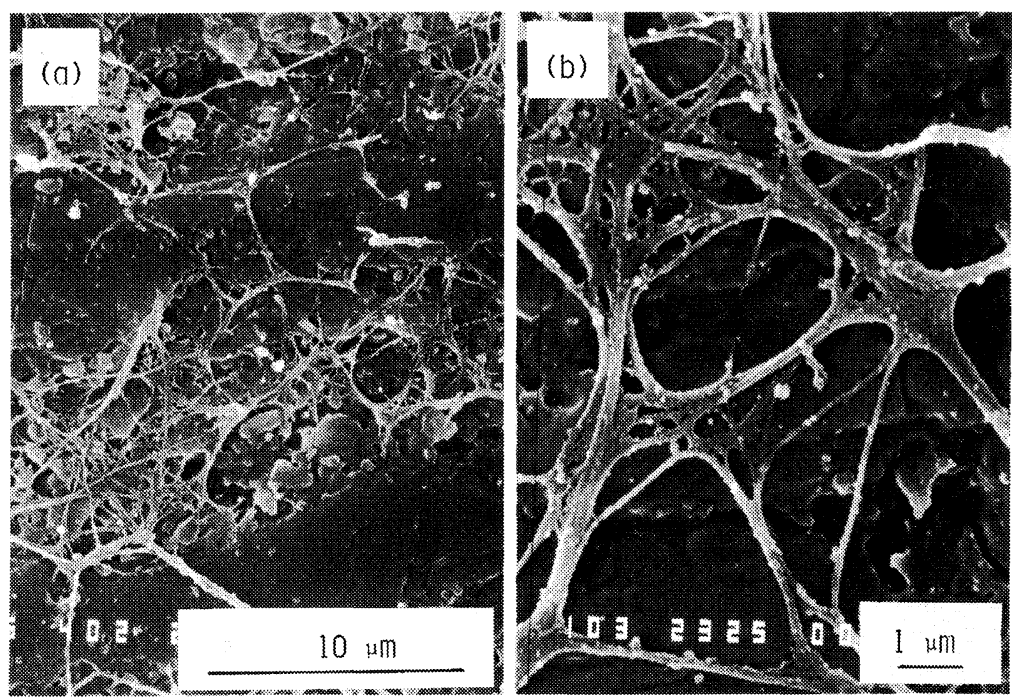

Figure 5. Scanning electron microphotographs of surface of implanted formulations (10 weeks). Magnification: (a) $4000 \times$, (b) $10000 \times$. 


\section{Yoshida et al.}

rats, e.g., 4 copolymer tablets/rat. The weight decrease in copolymer was within $0.001 \%$ after 10 weeks implantation, which was within gravimetrical error. From these results, it can be concluded that this copolymer has good biocompatibility and is scarcely degraded in vivo.

\section{Release Profile of LH-RH Agonist from Vinyl Copolymer Formulations}

Faure et al. have reported the pharmacological response in a clinical case when a des-Gly ${ }^{10}$-[D-Ser(TBU $\left.)^{6}\right]-$ LH-RH ethylamide at a dose of $50 \mu \mathrm{g}$ was injected subcutaneously once a day over a period of 8 months at a maximum. ${ }^{16} \mathrm{~A}$ biodegradable formulation (lactide-glycolide copolymer) including a D$\operatorname{Ser}(\mathrm{Bu})^{6}-\mathrm{Azgyl}^{10}$-LH-RH has been also reported to release the hormone in animals over a period longer than 28 days, depressing serum $\mathrm{LH}$ and testosterone, and reducing testes and accessory sex organ weights in rats. ${ }^{17}$ On the basis of these data, we tried to prepare two types of controlled release formulations with different release rates, which were about $1 \mathrm{mg}$ a day and $30 \mu \mathrm{g}$ a day. Both these formulations have sandwich structures as seen in Figure 2(5). The recovery of the drug from vinyl copolymer formulation was checked in order to find the loss of drug throughout the preparation processes (see Figure 2). That is, the formulation was pulverized to a powder, immersed in $0.1 \mathrm{M}$ phosphate buffer solution ( $\mathrm{pH}$ 7.2), and assayed spectrophotometrically. $49.1 \mathrm{mg}(98.2 \%$ of initial drug) and $4.7 \mathrm{mg}$ $(94.2 \%$ of initial drug) of drugs were recovered from the formulations containing $50 \mathrm{mg}$ and $5 \mathrm{mg}$ of initial drugs. It was concluded that the losses of drug throughout all the preparation procedures were negligibly small.

Results on the in vitro release of LH-RH agonist from vinyl copolymer formulation are shown in Figure 6. In a formulation system containing $5 \mathrm{mg}$ of $\mathrm{LH}-\mathrm{RH}$ agonist, the drug was released at a relatively constant rate of $16 \mu \mathrm{g} /$ day and such a constant rate was main-

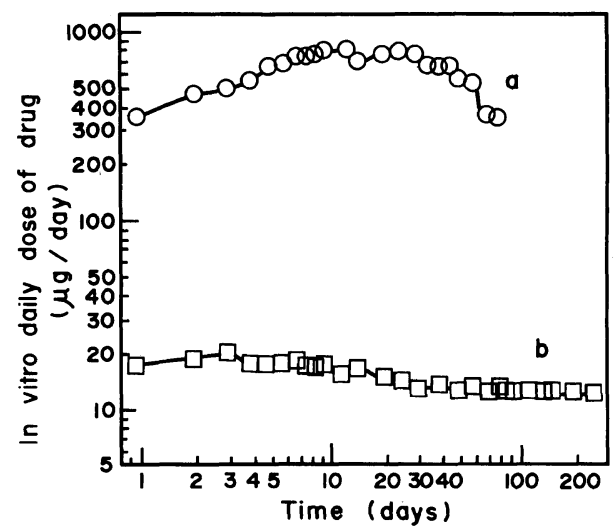

Figure 6. In vitro daily dose of LH-RH agonist from vinyl copolymer formulations having sandwich structure. Initial content of drug charged into a formulation: (a) $50 \mathrm{mg}$, (b) $5 \mathrm{mg}$.

tained during a whole experimental period of 250 days. A similar tendency was also observed in a $50 \mathrm{mg}$ drug-containing formulation system, though the constant release rate, $650 \pm 150 \mu \mathrm{g} / \mathrm{day}$, was not kept over a long period. In this case, the in vitro cumulative amount of drug released for 70 days was $45.9 \mathrm{mg}$. This value corresponded to $91.8 \%$ of initial drug charged in a formulation. Accordingly, it is obvious that in a formulation system containing $50 \mathrm{mg}$ of drug, the controlled release continuation is limited to within 70 days from the start. However, we also found that the release of drug at a constant rate of $600 \mu \mathrm{g} /$ day over longer than 200 days is possible using the drug-vinyl copolymer formulations having multiple sandwich structure. ${ }^{18}$

On the other hand, Figure 6 shows that the in vitro release of LH-RH agonist from a $50 \mathrm{mg}$ drug-containing formulation is about 40 times faster than that from a $5 \mathrm{mg}$ drug-containing formulation. The apparent surface area of the formulation used in this study is $4.8 \mathrm{~cm}^{2}$ and $0.86 \mathrm{~cm}^{2}$ in the above order. Accordingly, it is reasonable to conclude here that the extreme gap between the two release cannot be sufficiently explained by such factors as differences in concentration of the drug in the 
Table I. Comparison of in vitro and in vivo cumulative amounts of LH-RH agonist released from vinyl copolymer formulations having sandwich structures for a required period

\begin{tabular}{ccc}
\hline \multirow{2}{*}{$\begin{array}{c}\text { Time after } \\
\text { start of the } \\
\text { test/weeks }\end{array}$} & $\begin{array}{c}\text { Cumulative amount of drug released } \\
\text { from the formulation }\end{array}$ \\
\cline { 2 - 3 } & In vitro $^{\mathrm{b}}$ & In vivo $^{\mathrm{c}}$ \\
\hline 1 & $4.1( \pm 0.2)$ & $1.4( \pm 0.2)$ \\
2 & $9.7( \pm 0.3)$ & $3.3( \pm 0.2)$ \\
4 & $21.2( \pm 0.4)$ & $6.8( \pm 0.3)$ \\
6 & $31.7( \pm 0.9)$ & $11.4( \pm 0.4)$ \\
8 & $40.1( \pm 1.1)$ & $16.2( \pm 0.5)$ \\
10 & $45.9( \pm 0.9)$ & $22.5( \pm 0.5)$ \\
\hline
\end{tabular}

${ }^{a}$ Initial content of LH-RH agonist charged in to a sandwiched formulation is $50 \mathrm{mg}$.

b 5 Samples/group.

c 3 Rats/group.

formulation and in the surface area of the formulation. The main factor is not clear at present.

The vinyl copolymer formulation having the in vitro release profile in Figure 6a was implanted subcutaneously in the backs of rats. The in vivo cumulative amounts of drug released for required implantation period were compared with those in vitro and the relationship between the two releases is summarized in Table I. The cumulative amount of released drug was calculated from the amount of drug remaining in the formulations collected from $0.1 \mathrm{M}$ phosphate buffer solution as an elution medium in the in vitro experiments and from animals in the in vivo experiments. According to the results of Table I, the in vivo cumulative amount of released drug is significantly small in comparison with that in vitro. For example, the cumulative amounts of drugs released in vitro and in vivo during 10 weeks from the start were $45.9 \mathrm{mg}$ (average release rate: $650 \mu \mathrm{g} /$ day) and $22.5 \mathrm{mg}$ (average release rate: $320 \mu \mathrm{g} / \mathrm{day}$ ), respectively. The former is about twice the latter. In this case, the in vivo cumulative amount of drug released during the first 10 weeks period was about $45 \%$ of the initial drug. Such a retardation of in vivo release was similarly

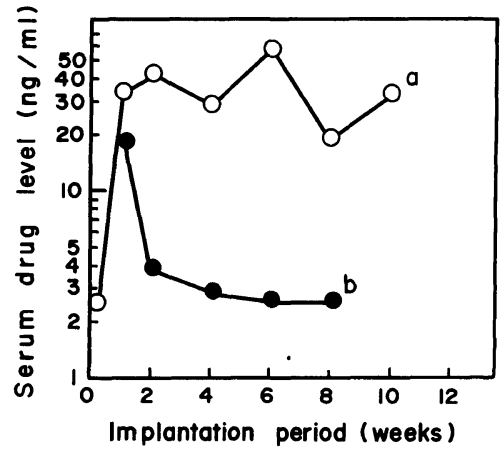

Figure 7. Changes of serum level of LH-RH agonist in male Wistar rats with controlled release formulations. Initial content of drug charged into a formulation: (a) $50 \mathrm{mg}$, (b) $5 \mathrm{mg}$.

observed in our clinical study for prostate cancer. $^{5}$ In the clinical case, the sandwich formulation was implanted below the right costalmargin. The results of the clinical study showed that the in vivo cumulative amount of LH-RH agonist released from a $100 \mathrm{mg}$ drugcontaining formulation for a period of 83 days from start of the test was $65.2 \mathrm{mg}(65.2 \%$ of initial drug). When the controlled release formulations consisting of hydrophilic poly(2hydroxyethyl methacrylate) and water-insoluble testosterone were implanted subcutaneously in castrated rats, the in vivo release of the drug was significantly retarded because of the thick fibrous capsules adhering to the surface of the implant. ${ }^{1}$ However, in the case of the hydrophobic-hydrophilic vinyl copolymer formulation system used in this study, the formation of thick fibrous capsules was not observed (see Figure 5). The difference in cumulative amounts of testosterone released in vivo and in vitro from the same hydrophobichydrophilic vinyl copolymer formulations was negligibly small, ${ }^{2}$ while in the case of LH-RH agonist, the in vivo cumulative amount of released drug was markedly more retarded than that in vitro. The reason for this is not clear, but it may be attributed to such factors as differences in molecular weight of the drug and solubility of the drug in the medium.

Figure 7 shows the changes in the serum 
level of the drug with the passage of time when the controlled release formulation was implanted subcutaneously in the backs of male Wistar rats. In a formulation containing $50 \mathrm{mg}$ of drug, its serum level was kept constant at about $30 \mathrm{ng} \mathrm{ml}^{-1}$ throughout the experimental period (10 weeks). The serum drug level showed a rapid decrease in the initial stage (up to 2 weeks) and then constant level $\left(2.5 \mathrm{ng} \mathrm{ml}^{-1}\right)$ in a formulation containing $5 \mathrm{mg}$ of drug, e.g., the serum drug level was $2.6 \mathrm{ng}$ $\mathrm{ml}^{-1}$ at the 8 th week and the in vivo cumulative release amount during the first 8 week period was $0.41 \mathrm{mg}$. It is reasonable to estimate that the average in vivo release rate of drug is $7 \mu \mathrm{g} /$ day in a $5 \mathrm{mg}$ drug-containing formulation.

The half-life of the LH-RH agonist in the serum was found to be $10.8 \mathrm{~min}$ in the alphaphase when administered intravenously, which was somewhat longer than the value for the half-life of the natural drug. When the LH-RH agonist in solution was injected subcutaneously, the maximal levels of the compound occurred at 10 to $20 \mathrm{~min}$. From these results, it can be proposed that this drug can be stably stored in a vinyl copolymer formulation over a very long period when implanted subcutaneously in animals.

\section{Changes in Serum Hormones Levels}

Figure 8 shows the changes in the serum levels of $\mathrm{LH}$ and testosterone in male Wistar rats with a $50 \mathrm{mg}$ drug-containing formulation. At the 1st day of the test, a large increase of both serum $\mathrm{LH}$ and testosterone levels was observed. However, these levels decreased below the initial levels (before implantation: serum testosterone level is 2.31 $\mathrm{ng} \mathrm{ml} l^{-1}$, serum $\mathrm{LH}$ level is $0.62 \mathrm{ng} \cdot \mathrm{sl} \mathrm{ml}^{-1}$ ) at about the 2nd week and then was maintained constant at a low level such as the castrate value throughout the experimental period (10 weeks). A possible explanation for the diminished gonadotropin secretion and serum testosterone level during chronic treat-

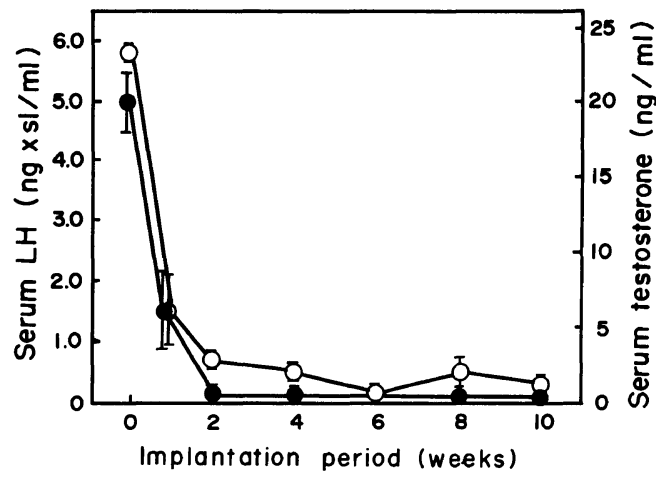

Figure 8. Changes of serum LH level and serum testosterone level in male Wistar rats with a controlled release formulation containing $50 \mathrm{mg}$ of LH-RH agonist. (O) serum LH level, ( $\square$ ) serum testosterone level.

ment with the controlled release formulation is the inhibitory effect on both pituitary and testicular functions. The profiles of $\mathrm{LH}$ and testosterone levels in Figure 8 are in good agreement with the results in prostate cancer patients to whom the LH-RH agonist of $20 \mathrm{mg}$ per day was injected with a continuous in fusion pump for 12 to 52 weeks. ${ }^{9}$

\section{Changes in Weight of Rat Prostate Glands}

The overall in vivo release rates of $\mathrm{LH}-\mathrm{RH}$ agonist from vinyl copolymer formulations containing $50 \mathrm{mg}$ and $5 \mathrm{mg}$ of drugs were found to be $320 \mu \mathrm{g} / \mathrm{day}$ and $7 \mu \mathrm{g} /$ day, respectively. The pharmacological response in male Wistar rats with the above formulation was investigated for changes in weight of the prostate gland and the results are shown in Figures 9, 10, 11, 12, and 13. For the purpose of comparison, the pharmacological response in male Wistar rats is also shown in Figure 9, $10,11,12$, and 13 when $20 \mu \mathrm{g}$ of drug was injected subcutaneously once a day over 8 weeks (aqueous solution of LH-RH agonist).

In the controlled release formulation of $\mathrm{LH}$ RH agonist, the weights of accessory sex organs such as ventral prostates, seminal vesicles, and dorsolateral prostates showed a remarkable decrease for a period up to 4 weeks from the start of the test and then kept con- 


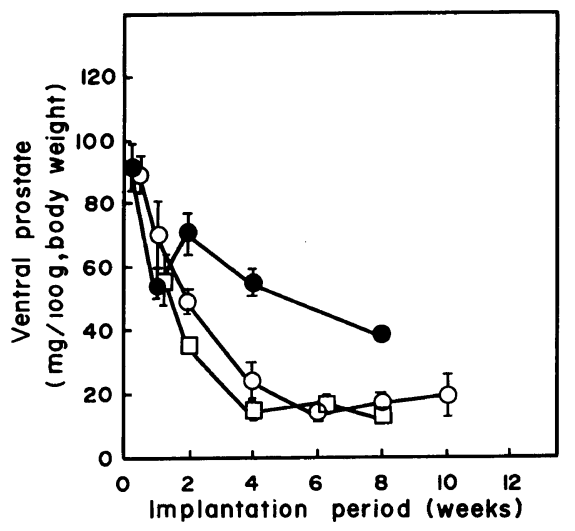

Figure 9. Changes of weight of the ventral prostates in male Wistar rats with controlled release formulations of LH-RH agonist. Type of controlled release formulation: (O) controlled release formulation containing $50 \mathrm{mg}$ of drug, $(\square)$ cotrolled release formulation containing $5 \mathrm{mg}$ of drug, (O) injection administration of drug in solution $(20 \mu \mathrm{g}$ of drug was administered subcutaneously once a day).

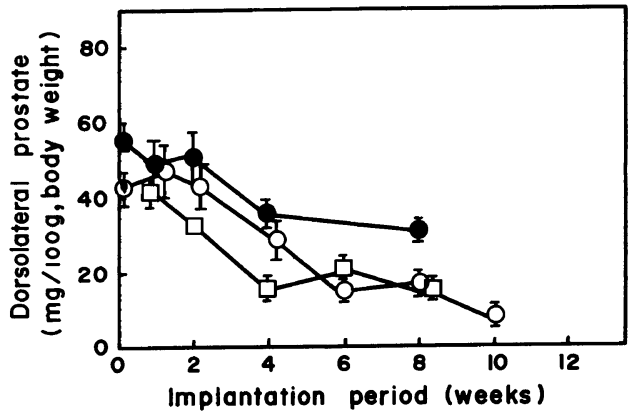

Figure 10. Changes of weight of the dorsolateral prostates in male Wistar rats with controlled release formulations of LH-RH agonist. Symbols in Figure refer to type of formulation given in Figure 9.

stant at approximately 10 to $20 \mathrm{mg} / 100 \mathrm{~g}$ of rat body weight, throughout the experimental period. However, differences in weight of rat prostates owing to different release rates were negligibly small according to the results of Figures 9, 10, and 11. Therefore, it was concluded that a sufficient pharmacological response to rat prostates can be obtained by the release of $7 \mu \mathrm{g} / \mathrm{day}$. Such reductions of rat prostates were comparable to those of castrate

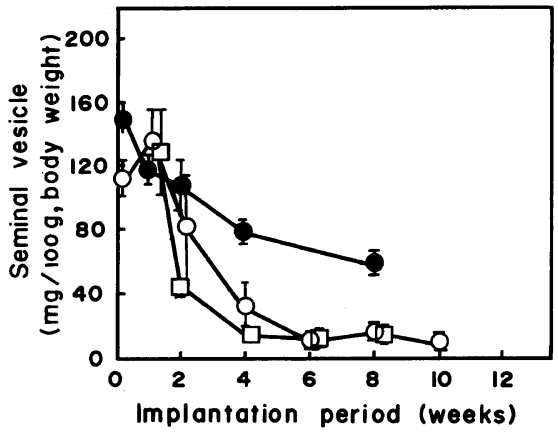

Figure 11. Changes of weight of the seminal vesicle (right only) in male Wistar rats with controlled release formulations of LH-RH agonist. Symbols in Figure refer to type of formulation given in Figure 9.

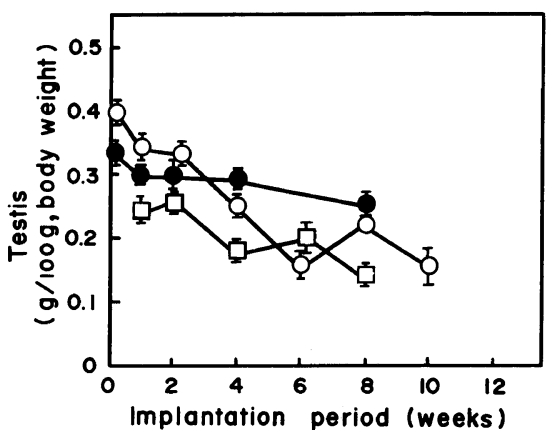

Figure 12. Changes of weight of the testis (right only) in male Wistar rats with controlled release formulations of LH-RH agonist. Symbols in Figure refer to type of formulation given in Figure 9.

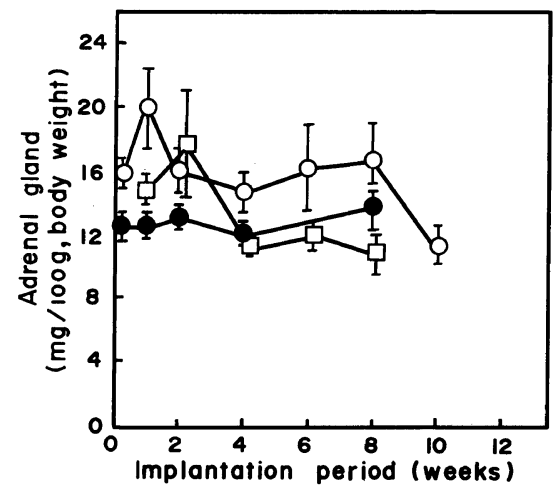

Figure 13. Changes of weight of the adrenal glands in male Wistar rats with controlled release formulations of LH-RH agonist. Symbols in Figure refer to type of formulation given in Figure 9. 
rats.

By an administration of the same drug ( $20 \mu \mathrm{g}$ once a day), the decrease in weights of accessory sex organs was smaller than that of controlled release formulation $(7 \mu \mathrm{g} /$ day in vivo). It is reasonable to conclude that the most effective efficacy by LH-RH agonist can be obtained by the controlled drug release from an implanted formulation. As shown in Figure 12 , the controlled release formulation caused a decrease in testes at the same time, whereas the weight of adrenal glands showed a slight increase with time (Figure 13).

\section{REFERENCES}

1. M. Yoshida, M. Asano, I. Kaetsu, K. Nakai, H. Yamanaka, T. Suzuki, K. Shida, and K. Suzuki, Biomaterials, 4, 33 (1983).

2. M. Yoshida, M. Asano, I. Kaetsu, K. Nakai, H. Yamanaka, K. Shida, and K. Suzuki, Polym. J., 14, 941 (1982).

3. K. Nakai, H. Yamanaka, M. Uehara, H. Yuasa, E. Takahashi, T. Suzuki, K. Shida, M. Yoshida, and I. Kaetsu, Horumon to Rinsho, 30, 1119 (1982).

4. T. Tamura, M. Go, D. Wada, K. Kunitomo, M. Takehara, M. Ando, M. Udaka, H. Yoshikawa, N. Komi, I. Kaetsu, and M. Yoshida, Gan to Kagakuryoho, 10, 41 (1983).

5. H. Yamanaka, K. Nakai, K. Shida, A. Shiraishi, M.
Yoshida, and I. Kaetsu, J. Steroid Biochem., 19, 12s (1983).

6. J. P. Gearhart, R. Witherington, and C. H. Coleman, Urology, 17, 44 (1981).

7. S. K. Chandrasekaran, R. Capozza, and P. S. L. Wong, J. Membrane Sci., 3, 271 (1978).

8. M. Yoshida, M. Asano, I. Kaetsu, H. Yamanaka, K. Nakai, H. Yuasa, and K. Shida, Abstracts of 103rd Meeting of the Pharmaceutical Society of Japan, Tokyo, 1983, p 160.

9. T. Makino and H. Yamanaka, Kitakanto Igaku, 33, 321 (1983).

10. M. Fujino, T. Fukuda, S. Shinagawa, S. Kobayashi, I. Yamazaki, R. Nakayama, Biochem. Biophys. Res. Commun., 60, 406 (1974).

11. C.Auclair, P. A.Kelly, D. H. Coy, A. V. Schally, and F. Labrie, Endocrinology, 101, 1890 (1977).

12. H. Okada, I. Yamazaki, Y. Sakurai, T. Yashiki, T. Shimamoto, and H. Miya, J. Pharm. Dyn., 6, 512 (1983).

13. I. Yamazaki and H. Okada, Endocrinol. Japon., 27, 593 (1980).

14. T. Makino, Foria Endocrinol. Japon., 49, 629 (1973).

15. K. Wakabayashi, Endocrinol. Japon., 24, 473 (1973).

16. N. Faure, F. Labrie, A. Lemay, A. Belanger, Y. Gourdeau, B. Laroche, and G. Robert, Fertility and Sterility, 37, 416 (1982).

17. B. J. A. Furr, B. E. Valcaccia, M. Sullivan, and F. G. Hutchinson, Abstracts of 74th Annual Meeting of the American Association for Cancer Research, San Diego, 1983, p 185.

18. M. Yoshida, M. Asano, I. Kaetsu, H. Yamanaka, K. Nakai, H. Yuasa, K. Shida, K. Wakabayashi, and K. Suzuki, Polym. Prepr. Jpn., 32, 1935 (1983). 